\title{
Um novo Brasil está para emergir? A eleição de Lula à presidência e o Brasil contemporâneo*
}

RESUMO

Neste artigo, Phillipe Joron apresenta um painel da sociedade brasileira contemporânea baseando-se na figura do presidente da República, Luiz Inácio Lula da Silva. Para Joron, que resgata a história do Brasil em 1500, passando pela Regência e outros períodos, Lula seria a encarnação fiel de forças que incomodam as bases culturais, econômicas e sociais. No entanto, diz ele, essa afirmação deve ser relativizada, não em função de seu contrário, mas, sobretudo, no que diz respeito ao seu conteúdo. A mobilidade vertical ou ascensão social do Brasil comprovam, segundo o autor, que a sociedade brasileira está mais do que nunca aberta às transformações.

\section{PALAVRAS-CHAVE}

mundialização

história

imaginário

\section{ABSTRACT}

In this article, Phillipe Joron presents a panel of the contemporary Brazilian society basing on the President Luiz Inácio Lula da Silva. For Joron, that rescues the history of Brazil in 1500, going by the Regency and other periods, Lula would be the incarnation of inconvenience forces in terms of cultural, economical and social bases. However, this theory is relative. The vertical mobility or social ascension of Brazil prove, according to the author, that the Brazilian society is more than never open to the transformations.

\section{KEY WORDS}

mundialização

history

imaginary
Em qualquer tomada de consciência, é preciso, às vezes, exagerar as dimensões do objeto que se tenta compreender, aumentando o traço ou se prevalecendo do absurdo. É o sentido, em todo caso, da notícia sobre a emergência de um Brasil supostamente diferente daquele que se conhecia até então: o Brasil muda, evidentemente, e a representação dessa mudança poderia servir de moeda de troca à escalada da mundialização. Brasil plural, comumente definido como "terra de contrastes" ou de paradoxos, país das oportunidades, para melhor ou pior. Mas estes qualificativos poderiam também se aplicar a qualquer outra nação, como aquelas que constituem, por exemplo, o frágil equilíbrio da Comunidade européia.

Retomando uma terminologia filosófica normalmente aplicada ao domínio religioso, existe, na aparência, um sincretismo brasileiro que se refere tanto aos próprios brasileiros quanto aos que contemplam esta identidade particular de fora. O sincretismo, no sentido figurado, remete à idéia de mistura ou de fusão sem que haja, necessariamente, conciliação entre os elementos, heterogêneos e mesmo incompatíveis entre si, constitutivos desse amálgama. É uma coabitação porosa, de qualquer forma, que não exclui totalmente as tensões ou as fricções forçosamente violentas entre os diversos universos que compõem a sociedade brasileira.

Este sincretismo não dissimula menos um ecletismo subjacente enraizado nas representações e nas práticas, que orienta, de qualquer forma, um modo de existência doloroso, e, no entanto, aberto à experiência. Pois o ecletismo, antes que lhe seja dada uma significação ligada à dispersão ou à explosão dos centros de interesse, compreende-se, primeiramente, como uma composição sistêmica, como uma junção dos fragmentos dispersos nos quais as verdades antinômicas ou sucessivas possam entrar em sinergia e alcançar, assim, a expressão de uma ordem de verdade superior.

De acordo com esse ponto de vista, existe, me parece, uma poeira ou uma lama de fundo não mais sincrético, mas também eclético, que dinamiza a mentalidade brasileira. Ecletismo que se encontra no tema de que nos ocupamos aqui: um Brasil novo está prestes a emergir? Se for o caso, seu presidente atual, Luiz Inácio Lula da Silva, figura emblemática de um povo que assumiu seu próprio destino, serve de catalisador ou de afirmação dessa mudança? Com sua insustentável ingenuidade ou sua incomensurável pretensão, esta interrogação, "Lula" ao menos, não é nova. Nós a encontramos em filigrana, sob forma de asserção ideológica e geoestratégica, antes mesmo da descoberta em 1500 desta terra exuberante, já que o Tratado de Tordesilhas, assinado pelo menos seis anos antes pelos soberanos de 
Espanha e de Portugal, traçava já a linha de demarcação das conquistas territoriais destas duas nações ibéricas no Novo Mundo, fazendo emergir, assim, um Brasil virtual. Terra Incognita, cheia de promessas, apesar da existência consagrada à periferia longínqua do Velho Mundo.

Para além dos numerosos Brasis coloniais abertos à elasticidade tumultuosa das fronteiras sempre negociáveis, se afirma a independência política de 1822, arrancada de Portugal por Dom Pedro I. O Brasil torna-se, então, um império, e continuará a sêlo por causa de suas dimensões, suas possibilidades naturais, industriais e humanas, com Dom Pedro II, mas também até que seja declarada a República em 1889. Um império não tanto para Portugal e sim para investidores estrangeiros que exercem toda sorte de influências, das menos às mais nefastas: influências estas de cunho econômico, certamente, mas também nos sentidos político e cultural. Na mesma perspectiva, as potências nacionais contribuem ativamente para o modelo civilizatório deste laboratório a céu aberto. Foi o caso dos anos que se seguiram à constituição da República, no final do século XIX, e, também, na Era Vargas, ou, ainda, no período das juntas militares século XX.

\section{Quinhentos anos de história de uma nação não é grande coisa, poderíamos alegar. Mas é, sem dúvida, mais do que necessário para se experimentar 0 impacto das culturas entre si e a escalada crescente de sua sinergia.}

O povo brasileiro não tinha qualquer direito de ação sobre este império? E, ainda: deseja, verdadeiramente, ou é suficientemente preparado para tomar o seu próprio destino pelas mãos? Estas mesmas questões são relevantes no presente, na Era Lula? Para sermos justos, mesmo que minimamente justos, a resposta deve ser eclética. Os brasileiros adoram representar seu país como uma nação jovem (populacional e historicamente falando). Um povo que teria, pois, as qualidades e defeitos do seu frescor. Um país imaturo para o qual é preciso dar um tempo para que amadureça sua experiência de alteridade. Um país repleto de potencialidades em que o presente se encontraria, acima de tudo, no futuro. ${ }^{1}$ O que não pode ser ainda resolvido deve sê-lo, necessariamente, pelo movimento dialético da História. Esta imagem é também amplamente aceita sobre o Velho Continente. Paris Match intitulava assim um número especial sobre o Brasil: "Brésil danse avec le futur" ("Brasil dança com o futuro"). E acrescentava: "É neste país-continente que estão em jogo os próximos desafios do planeta" 2 . Eu mencionei acima o laboratório a céu aberto, o que Michel Maffesoli entende, por sua vez, como um laboratório da pós-modernidade. Experimenta-se a miscigenação que já construiu nossas mentalidades e nossos corpos na era da mundialização e da intercomunicação: um caldeirão étnico e cultural que dá o que pensar e fazer. Experimenta-se, também, o relativismo, o irracionalismo, o presenteísmo, a ruína dos grandes ideais herdados da Filosofia das Luzes, a bricolagem dos usos e costumes.

Quinhentos anos de história de uma nação não é grande coisa, poderíamos alegar. Mas é, sem dúvida, mais do que necessário para se experimentar o impacto das culturas entre si e a escalada crescente de sua sinergia. Em Maîtres et esclaves ("Senhores e escravos"), Gilberto Freyre assinala a formação da sociedade brasileira como uma dinâmica de afrontamento e de ajuste entre os modelos culturais e econômicos profundamente diversos. "É verdade, diz ele, que entre todos estes antagonismos que se chocam, houve sempre, para amortecê-lo ou harmonizá-lo, forças de confraternização e de mobilidade vertical, próprias ao Brasil" ${ }^{\prime 3}$. Sem dúvida, pode-se ver, então, em Lula, a encarnação fiel daquelas forças que incomodam as bases culturais, econômicas e sociais. Mas esta afirmação deve ser relativizada, não em função de seu contrário, mas, sobretudo, no que diz respeito ao seu conteúdo. Mobilidade vertical ou ascensão social que mostram que a sociedade brasileira está mais do que nunca aberta às transformações.

Eu utilizei, voluntariamente, os termos "encarnação exemplar" e "figura emblemática" para significar o elo íntimo que liga o povo brasileiro ao mais alto representante da nação. Este elo, simbolicamente falando, deve necessariamente existir para que se instale e perdure a legitimidade do poder, qualquer que seja sua natureza. Na sociologia, os trabalhos de Max Weber sobre a dominação, entendida como manifestação concreta do poder, nos permite distinguir suas três formas expressivas: a dominação tradicional, carismática e legal ou racional. Neste último tipo de dominação, que corresponde à organização política escolhida pela maioria dos estados modernos, entre os quais a República Federativa do Brasil, a burocratização dos aparatos legislativo, executivo e judiciário se exerce sob o controle administrativo do corpo de funcionários ou servidores do Estado, respeitando-se a lei e as próprias instituições. Em última instância, no entanto, é o Estado que representa a autoridade e, portanto, o modo de domínio legal. Na verdade, a administração burocrática pode ser encarada como um instrumento 
de dominação pelo saber especializado e conhecimento da engrenagem própria à organização do Estado, o que confere poder e prestígio aos funcionários, nos limites de suas atribuições. Significa, também, a dominação da impessoalidade: o funcionário, responsável por seu cargo e por seus deveres inerentes a sua função, aplica as leis, sem qualquer restrição, para o bem comum. A organização da burocracia racional só faz sentido em relação a esse tipo de impessoalidade estrutural. As relações pessoais são limitadas, assim, ao mínimo contato possível, para que elas sejam preservadas da arbitrariedade e dos jogos de influência. Caso contrário, poderia haver espaço para a entrada em cena dos valores da dominação tradicional ou carismática: a amizade, o parentesco, o dinheiro.

Segundo Weber, este ideal-tipo, enquanto forma estável de dominação, pode, no entanto, entrar em correspondência com certas características da dominação tradicional e/ou carismática. Na verdade, a dominação tradicional se apóia "na crença cotidiana na santidade das tradições válidas em todos os tempos e na legitimidade daqueles que são chamados a exercer a autoridade por tais meios" ${ }^{\prime 4}$. De forma que o representante do poder deve ser obedecido, sem que seja colocada em causa sua legitimidade, na medida em que é o costume que justifica este fato: redundância intemporal da existência e da prática deste poder e, pois, de certo tipo de organização social. O paternalismo e o clientelismo brasileiros, exacerbados no coronelismo, a respeito do qual falaremos mais adiante, constatados tanto no exercício do poder quanto em uma escala macro e micro-política, integram, em parte, esta dinâmica de invariância das relações sociais fundada na submissão, na punição e na recompensa. Quanto à dominação carismática, é uma autoridade "fundada pelo encanto pessoal e extraordinário de um indivíduo (carisma). Ela se caracteriza pela devoção pessoal das pessoas à causa de um homem e por sua confiança na sua única pessoa ao se destacar por suas qualidades prodigiosas, como o heroísmo ou outras particularidades exemplares de um chefe" ${ }^{\prime \prime}$. A dominação carismática é, pois, uma forma de poder na qual a legitimidade repousa menos em leis debatidas nas assembléias (dominação racional) ou nos costumes ancestrais (dominação tradicional) do que sobre o Verbo e o Gesto daquele que a exerce. Retomando aqui uma idéia de Emile Durkheim, adaptando-a aos contornos do nosso tema, poderíamos dizer que a sociedade brasileira é uma "máquina de fazer deuses" 6 , à imagem de suas práticas religiosas plurais que a ajudam, sem dúvida, a justificar sua existência.

A administração federal brasileira, junto ao seu modo político de pensar, assimilou tanto os ingredientes tradicionais quanto carismáticos da dominação e os incorporou à sua concepção legal ou racional da alteridade pelo poder. Pode-se ver nisso o efeito de uma ambivalência constitutiva e também adaptativa que se encontra em todos os níveis da sociedade. $\mathrm{O}$ elemento tradicional da dominação no Brasil é, de certa forma, representado por aquilo que se chamou o coronelismo ${ }^{7}$ ou poder dos coronéis, que surgiu sob uma forma institucional com a criação em 1831 da Guarda Nacional. O governo da Regência (1831-1842) colocou à venda todos os postos militares do Império e os títulos que foram, então, adquiridos pelos grandes proprietários de terra e outros ricos comerciantes, mais tarde os barões da indústria, os quais podiam formar uma espécie de milícia. A detenção do poder econômico se travestia, pois, de um poder político considerável, já que a representação da ordem (nacional, local) nas mãos de uma elite de civis reforçava ainda mais a significação material e simbólica do poder de posse. Era um poder privativo, essencialmente rural, geograficamente e mentalmente distante das exigências constitucionais das grandes cidades, mantido por um homem tendo direito de vida e de morte sobre os que afrontavam sua autoridade, mesmo que ela fosse juridicamente condenável. Logo, um poder incontestável, mas que para se consolidar e se ampliar devia manter três de seus principais elementos de fundação: primeiro, a posse e a extensão territorial, suprema expressão de riqueza; depois, a família a ampliação de suas ramificações por meio de casamentos arranjados, tendo o Coronel inteira influência sobre todas as instâncias locais da decisão; finalmente, os afilhados, compostos de parentes distantes, de protegidos e similares que permitiam ao Coronel disseminar sua aura junto à população, bem como estendê-la para além de sua própria região ou seu próprio centro de influência.

O elemento carismático de dominação toma forma no Brasil a partir da contestação do poder, em particular contra o coronelismo e a Velha República (1889-1930), culpados de terem, de certa forma, pervertido as promessas deste paraíso terrestre, e que, para a maioria, ainda se encontrava entre a miséria e a alienação. Vários movimentos messiânicos surgiram, entre os quais os mais célebres foram os que tiveram um fim trágico, o da Guerra dos Canudos, em 1897, e o do Contestado, em 1916. Se o impulso destes dois movimentos é de natureza religiosa, a exemplo de seus dois líderes, respectivamente Antônio Vicente Mendes, dito Conselheiro, no sertão baiano, e João Maria de Jesus, no estado de Santa Catarina, também o era do ponto de vista social e político. Era um desejo, em todo caso, de uma alternativa radical aos ditames das elites e de seus sistemas opressivos: a exploração de outra via social, política e religiosa, através do comunitarismo e do milenarismo, ou seja, pela socialização da terra e dos bens dos quais os líderes desses movimentos foram excluídos ou despossuídos.

É bom lembrar que estas duas formas específicas de dominação tradicional e carismática, vistas aqui em 
termos de coronelismo e de messianismo, no que diz respeito ao Brasil, podem ser totalmente opostas, como foi o caso nos conflitos mencionados anteriormente, ou mesmo em total complementaridade, a exemplo do Padre Cícero no Ceará, Coronel e também figura carismática do catolicismo popular. E o que o Brasil contemporâneo tem a ver com tudo isso? Eu disse, acima, que o percurso biográfico de Lula significava uma revanche pessoal contra uma situação social, econômica e política construída a golpes de fatalidade e, porque não dizer, de fatalismo. Sua história é também a de dois Brasis que se encontram. $\mathrm{O}$ da região Nordeste, de onde saiu Lula (Pernambuco), que conta com mais de 50 milhões de habitantes, essencialmente rural e pobre, economicamente falando. ${ }^{8} \mathrm{O}$ da região Sudeste, em direção à qual emigrará o jovem Lula (São Paulo), que conta com mais de 75 milhões de habitantes, fortemente industrializada e rica, economicamente falando. É a história de milhões de brasileiros que, ao longo da segunda metade do século $X X$, procuraram um destino economicamente viável, fugindo da seca, da miséria ou da esclerose social, na esperança de, primeiro, encontrar um trabalho e, em seguida, um valor decente para este mesmo trabalho. Uma nova chance. Uma chance tout court (em essência).

Antes dele, um personagem carismático sonhara em dar asas ao Brasil, então à mercê das oligarquias rurais e de seu sistema de favores baseado no clientelismo: Getúlio Vargas. ${ }^{9}$ Depois da Revolução dos Tenentes, em 1930, e principalmente na afirmação do Estado Novo, entre 1937 e 1945, este último irá se dedicar em reforçar a centralização da administração e do poder, tomando medidas ofensivas contra o Coronelismo. Ele ampliará o poder de voto nos grandes centros urbanos, dando o direito de voto às mulheres e instaurando o voto secreto (cuja ausência até então era instrumentalizada pelos Coronéis). É também sob sua ditadura que se ampliará a industrialização do país, tendo por consequiência a emergência de uma consciência trabalhista que poderá beneficiar, sob seu mandato, a implantação de leis trabalhistas e de organizações sindicais.

Lula nasceu em 1945, ou seja, no apogeu da Era Vargas. (Sua vida de metalúrgico começou aos 14 anos de idade, ao mesmo tempo seu aprendizado de uma consciência política pela via do sindicalismo, primeiramente, pois ele se tornará presidente do Sindicato dos Metalúrgicos da Grande São Paulo, em 1975), e, depois, pela criação do Partido dos Trabalhadores, em janeiro de 1980. A formação dessa consciência política é contemporânea às ditaduras dos generais entre 1964 e 1979, que, sob o pretexto do perigo vermelho e da defesa da democracia, se preocupou, durante uma quinzena de anos, a neutralizar as forças de esquerda (incluindo intelectuais, artistas, estudantes, jornalistas, ou qualquer pessoa que não aderisse à visão dos militares e de seus correligionários), sobretudo o Partido Comunista e os sindicatos de trabalhadores suspeitos de propagar sua ideologia.

\section{Lula representava, então, essa possível mudança, ou, em todo caso, uma nova tomada de consciência das prioridades até então deixadas de lado pelas políticas governamentais anteriores.}

À frente do Partido dos Trabalhadores, que se beneficia da abertura do país ao sistema democrático, Lula deseja, a partir de então, aplicar seu ideal de justiça social não apenas à categoria dos trabalhadores do setor da indústria, mas também a todos que sofriam por causa de um sistema falho em termos de repartição eqüitativa das riquezas, a todos os excluídos. ${ }^{10}$ Se a consciência sindical era fundamental para a conquista dos direitos e, sobretudo, para a sua aplicação, faltava na paisagem política brasileira uma entidade com aspirações sociais fortes. Após ter sido derrotado três vezes seguidas nas eleições presidenciais, em 1990 (contra Fernando Collor), em 1994 e 1998 (contra Fernando Henrique Cardoso), Lula obtém, finalmente, as rédeas do poder em outubro de 2002. Fernando Collor, primeiro presidente eleito em sufrágio direto depois da ditadura dos generais, representava a juventude e o dinamismo econômico, mas também certo dandismo. Mas este ideal escondia, também, uma corrupção mais que tendenciosa que lhe valera, dois anos mais tarde, sua destituição. Fernando Henrique Cardoso, sociólogo, representava, por sua vez, um saber acadêmico em relação ao trato político, econômico e social do país. Sua eleição, em outubro de 1994, se deve, em grande parte, a sua política de estabilidade monetária e de controle da inflação, instaurada alguns meses antes quando fora ministro de Economia no governo Itamar Franco (presidente interino).

Em 2002, a estabilidade econômica do país era certamente frágil, mas incontestável. Faltava, sem dúvida, uma política social mais contundente em favor das classes menos favorecidas, nas quais se achava também uma boa parte da classe média. Lula representava, então, essa possível mudança, ou, em todo caso, uma nova tomada de consciência das prioridades até então deixadas de lado pelas políticas governamentais anteriores. Lula é, enfim, a elaboração de um presente menos injusto. Os objetivos 
são claros e em via de realização. Primeiro, uma redução significativa da fome em todo o território nacional (Programa Fome Zero). Depois, a extensão do programa Bolsa Família, que beneficiou 7,5 milhões de famílias em 2005 para um orçamento de 11 milhões de reais. ${ }^{11}$ Enfim, a implantação do micro-crédito: mais de 6 milhões de pessoas foram integradas ao sistema bancário brasileiro até 2005, gerando, assim, mais de 9 milhões de operações de crédito para um total de 2 bilhões de reais (com uma taxa mínima de crédito de $4 \%$ ao mês). Esta última medida permitiu não apenas o financiamento de milhares de microempresas, mas também uma dinamização do consumo. Não se pode esquecer, para além das condições materiais, a dimensão simbólica destas iniciativas: reconquista e, para muitos, a descoberta do estatuto da humanidade.

O carisma de Lula contribuiu e muito para isso. Se ele representa uma nação, como todo chefe de Estado, encarna, sobretudo, seu povo, com seus deslizes, mas, também, sua capacidade de composição. Sem querer desenhar aqui um quadro idílico da simbólica "lulana" , é preciso, no entanto, admitir certa ruptura na continuidade, como dizem os políticos, e talvez mesmo pela continuidade. Eu falei da composição, e é bem isso do que se trata: iniciar uma curva, mas tendose em conta a sinalização do novo código. Um código de boa conduta, de qualquer forma, que não assuste investidores estrangeiros e nem grandes proprietários da riqueza nacional, mas que tente, porém, resgatar os despossuídos à margem do caminho. Uma nova direção ou perspectiva que leve em conta a realidade do terreno, com seus acidentes e suas potencialidades. Uma política que se apóie sobre o carisma de um homem, para dar sentido à dominação racional ou legal indicada mais acima, trombando com tentativas de dominação tradicional (clientelismo), sob o risco de imitar, às vezes, suas práticas para a realização de seus objetivos $^{12}$-FAMECOS

\section{NOTAS}

* Tradução: Eduardo Portanova Barros. Bolsista CNPq-Brasil.

1 ZWEIG, Stefan. Brasil, país do futuro. Rio de Janeiro: Nova Fronteira, 1981.

2 Match du Monde, $N^{\circ}$ 1, mars-avril 2005.

3 FREYRE, Gilberto. Maîtres et esclaves. Paris: Gallimard, p.93, 1974.

4 WEBER, Max. Economie et société. Paris: Plon, p. 222, 1971.

5 WEBER, Max. Le savant et le politique. Paris: Plon, p. 102, 1959.
6 Ver também MOSCOVICI, Serge. La machine à faire des dieux. Paris: Fayard, 1988.

7 Sobre esta questão remetemos ao artigo de Voltaire Schilling, Ascensão e queda do coronelismo, Disponível em <http://educaterra.terra.com.br/ voltaire $/ 500 \mathrm{br} /$ coronelismo.htm>. Acessado em: 05 mai 2009.

8 Segundo dados do último recenseamento demográfico em 2000 pelo Instituto Brasileiro de Geografia e Estatística (IBGE), a população da região Nordeste era de 47.693.253 pessoas, enquanto que a da região Sudeste contava 72.297.351, fazendo dessas duas regiões as mais populosas sobre um total de 169.590. 693 pessoas, totalizando o território nacional.

9 Ver sobre o tema o romance de SILVA, Juremir Machado da. Getúlio. Rio de Janeiro: Record, 2004.

10 Segundo os últimos dados do IBGE, em 2003, 53,8\% dos brasileiros com mais de 10 anos recebem um máximo de dois salários mensais, ou seja, menos de R\$ 320 (120 Euros). A taxa de desemprego em 2002 era de $7,1 \%$.

11 Segundo o jornal O Globo, sábado, 15 de outubro de 2005.

12 As revelações em abril 2005 sobre o caso dos Mensalões - suposta compra de votos por deputados do Partido dos Trabalhadores junto aos deputados de oposição - são uma ilustração particularmente reveladora desse tipo de manobra. Mesma coisa no que diz respeito ao autoritarismo de Lula, ao final do primeiro semestre de 2004, quando ele decidiu suprimir o visto de um jornalista americano que tinha publicado um artigo no qual questionava certa inclinação do Presidente pela bebida, colocando em xeque sua política governamental.

\section{REFERÊNCIAS}

FREYRE, Gilberto. Maîtres et esclaves. Paris: Gallimard, 1974.

WEBER, Max. Economie et société. Paris: Plon, 1971.

WEBER, Max. Le savant et le politique. Paris: Plon, 1959.

ZWEIG, Stefan. Brasil, país do futuro. Rio de Janeiro: Nova Fronteira, 1981. 